Research article

urn:1sid:zoobank.org:pub:22068428-1F40-4A9B-BDB9-87694799EC52

\title{
The genus Parbatthorax Tanasevitch, 2019 (Araneae, Linyphiidae) new to China, with a new species from the Gaoligong Mountains
}

\author{
Muhammad IRFAN ${ }^{1} \&$ Xianjin PENG $^{2, *}$ \\ ${ }^{1,2}$ College of Life Sciences, Hunan Normal University, Changsha, Hunan 410081, China. \\ *Corresponding author: xjpeng@126.com \\ ${ }^{1}$ Email: irfanuos94@yahoo.com \\ ${ }^{1}$ urn:lsid:zoobank.org:author:4EE226DB-D810-4907-A4B6-B04F4E4241AB \\ ${ }^{2}$ urn:1sid:zoobank.org:author:412B1D1C-E9C8-4F0F-9F1C-F2A9AEE10044
}

\begin{abstract}
Parbatthorax proiectus sp. nov. ( $\hat{\jmath}$ ) is described from the Gaoligong Mountains in Yunnan, China. A detailed morphological description, photographs of the body and copulatory organs, line drawings of the copulatory organs, as well as a locality map are provided.
\end{abstract}

Keywords. Description, Erigoninae, morphology, taxonomy, Yunnan.

Irfan M. \& Peng X. 2019. The genus Parbatthorax Tanasevitch, 2019 (Araneae, Linyphiidae) new to China, with a new species from the Gaoligong Mountains. European Journal of Taxonomy 555: 1-11.

https://doi.org/10.5852/ejt.2019.555

\section{Introduction}

Yunnan is a biodiversity-rich spot in South China. About eight genera and 38 species of linyphiid spiders have been described from there (Wunderlich \& Song 1994; Xia et al. 2001; Liu \& Chen 2010; Zhao \& Li 2014; Irfan \& Peng 2018).

The genus Parbatthorax Tanasevitch, 2019 presently only comprises the type species Parbatthorax unicornis Tanasevitch, 2019 (male only) from Nepal (Tanasevitch 2019). While examining the specimens collected from the Gaoligong Mountains under the joint Sino-American biodiversity survey of the California Academy of Sciences (CAS) and the Hunan Normal University (HNU) from 1998 to 2006, Parbatthorax proiectus sp. nov. was recognized as a new species, which is described here.

\section{Material and methods}

Specimens were collected by sieving and are kept in $75 \%$ ethanol. After dissecting from the body, the epigyne was cleared in a trypsin enzyme solution before examination and photography. The left male palp was used for description and illustration. Specimens were examined and measured with a Leica M205C stereo microscope. Photographs were taken with a Canon PowerShot G12 digital camera mounted on an Olympus BX53 and a Leica MC170 HD mounted on a Leica M205C; compound focus images were generated using Helicon Focus software (ver. 3.10, free software). The map was created in ArcMap ver. 10.2 and then modified in Adobe Photoshop CS2 Extended (Fig. 7). All the specimens included in 
the present study are deposited at the College of Life Sciences, Hunan Normal University, Changsha (China).

Leg measurements are given in the following order: total length (femur, patella + tibia, metatarsus, tarsus). All measurements are given in millimeters (mm).

Abbreviations used in the text and figures are as follows:

$\begin{array}{ll}\text { AER } & =\text { anterior eye row } \\ \text { ALE } & =\text { anterior lateral eyes } \\ \text { AME } & =\text { anterior median eyes } \\ \text { AME-ALE } & =\text { distance between AME and ALE } \\ \text { AME-AME } & =\text { distance between AME } \\ \text { AME-PME } & =\text { distance between AME and PME } \\ \mathrm{C} & =\text { convector } \\ \text { CD } & =\text { copulatory duct } \\ \text { CO } & =\text { copulatory opening } \\ \text { DAC } & =\text { distal apophysis of convector } \\ \text { DP } & =\text { dorsal plate } \\ \text { DSA } & =\text { distal suprategular apophysis } \\ \mathrm{E} & =\text { embolus } \\ \text { FD } & =\text { fertilization ducts } \\ \text { HS } & =\text { horn-shaped spine } \\ \text { PC } & =\text { paracymbium } \\ \text { PER } & =\text { posterior eye row } \\ \text { PLE } & =\text { posterior lateral eye } \\ \text { PME } & =\text { posterior median eye } \\ \text { PLE-PLE } & =\text { distance between PLE } \\ \text { PLE-PME } & =\text { distance between PLE and PME } \\ \text { PME-PME } & =\text { distance between PME } \\ \mathrm{R} & =\text { radix } \\ \text { S } & =\text { spermathecae } \\ \text { SPT } & =\text { suprategulum } \\ \text { ST } & =\text { subtegulum } \\ \text { T } & =\text { tegulum } \\ \text { Tm } & =\text { trichobothria } \\ \text { VP } & =\text { ventral plate } \\ & \end{array}$

The terminology used in text and figure legends follows Tanasevitch (2019).

\section{Results}

Class Arachnida Cuvier, 1812

Order Araneae Clerck, 1757

Family Linyphiidae Blackwall, 1859

Genus Parbatthorax Tanasevitch, 2019

\section{Type species}

Parbatthorax unicornis Tanasevitch, 2019. 


\section{Parbatthorax proiectus sp. nov. urn:1sid:zoobank.org:act:29B068AE-D2E4-4BC7-813D-197825629C3D}

Figs $1-7$

\section{Diagnosis}

The new species is closely related to Parbatthorax unicornis Tanasevitch, 2019 in having the male carapace modified with a thick horn-shaped spine and the palp with a similar embolic division (Figs 1-4; Tanasevitch 2019: figs 1-8). It can, however, be distinguished by the denticulate tibial apophyse and the highly modified paracymbium in the new species (Figs 2A-D, 3A-B, 4A-B), whereas the tibial teeth are absent and the paracymbium is less modified in P. unicornis (Tanasevitch 2019: fig. 3).

\section{Etymology}

The species name comes from the Latin adjective 'proiectus' meaning 'protruding' and refers to the projections on the distal margin of the male palpal tibia. The gender is masculine.

\section{Material examined}

\section{Holotype}

CHINA - Yunnan Province - ô; Lushui County, Pianma Township, Chanyan He, $9.3 \mathrm{~km}$ ESE of Pianma; 25.99363 ${ }^{\circ}$ N, 98.66651 ${ }^{\circ}$ E; 2470 m a.s.l.; 14 May 2005; Charles Griswold leg.; mixed broadleaf deciduous and evergreen forest; beating understory vegetation; HNU CGY107.

\section{Paratypes}

CHINA - Yunnan Province • $11 \hat{\partial} \widehat{\partial}, 14$ $\propto$ \% ; same collection data as for holotype; HNU CGY107 • 2 ડึ,, 5 우; Mingguang Township, Zizhi Village; $25.78277^{\circ} \mathrm{N}, 98.61633^{\circ} \mathrm{E} ; 2200 \mathrm{~m}$ a.s.1.; 21 May 2006; Ming-wei Yang leg.; HNU YHY10 • 2 + ; Tengchong County, Jietou Township, Datang Village, on the road from Daheling Ganjiao to Dashu Dujuan; $25.42018^{\circ}$ N, $98.40946^{\circ}$ E; 2430 m a.s.1.; 17 May 2006; Xian-jin Peng, Xin-ping Wang and Peng Hu leg.; HNU Peng060517 • 1 P; Jietou Township, Datang Village, Daheling Ganjiao; $25.74556^{\circ}$ N, $98.69630^{\circ}$ E; 2030 m a.s.1.; 15 May 2006; Xian-jin Peng, Xin-ping Wang and Peng Hu leg.; HNU Peng060515 • 1 क ; Gongshan County, Dulongjiang Township, $\mathrm{S}$ of Dizhengdang Village along Silalong He above main N/S road; $28.07654^{\circ} \mathrm{N}, 98.32603^{\circ} \mathrm{E} ; 1890 \mathrm{~m}$ a.s.1.; 28 Oct. 2004; D.H. Kavanaugh leg.; HNU DHK-2004-058A.

\section{Description}

\section{Male}

Body AND HEAD. Total length 1.52-1.76. Holotype (Figs 1A-B, 3C-D): total length 1.58. Carapace brown, 0.58 long, 0.61 wide; cephalic lobe 0.29 long; fovea, cervical and radial grooves distinct; ocular region with three thick, horn-like spines. Clypeus 0.31 high. Sternum longer than wide, dark brown, with spine-like hairs. Labium wider than long; maxillae long, distal end broad, with scopulae. Chelicerae with three promarginal and four retromarginal teeth. Eye region narrow, AER straight, PER procurved, slightly wider than ARE, PME present on cephalic lobe. Eye sizes and interdistances: AME 0.04, ALE 0.06, PME 0.06, PLE 0.05, AME-AME 0.03, PME-PME 0.07, AME-ALE, 0.01, PME-PLE 0.05, AME-PME 0.11, ALE-ALE 0.20, PLE-PLE 0.24, ALE-PLE contiguous.

LEG MEASUREMENTS. I $2.62(0.71,0.86,0.63,0.42)$, II $2.55(0.70,0.83,0.61,0.41)$, III $2.08(0.62,0.64$, $0.48,0.34)$, IV $2.5(0.69,0.79,0.65,0.37)$.

Leg Formula. I-II-IV-III. TmI 0.32 and TmIV 0.27.

Tibial SPINE FORMULA. $2-2-1-1$. 


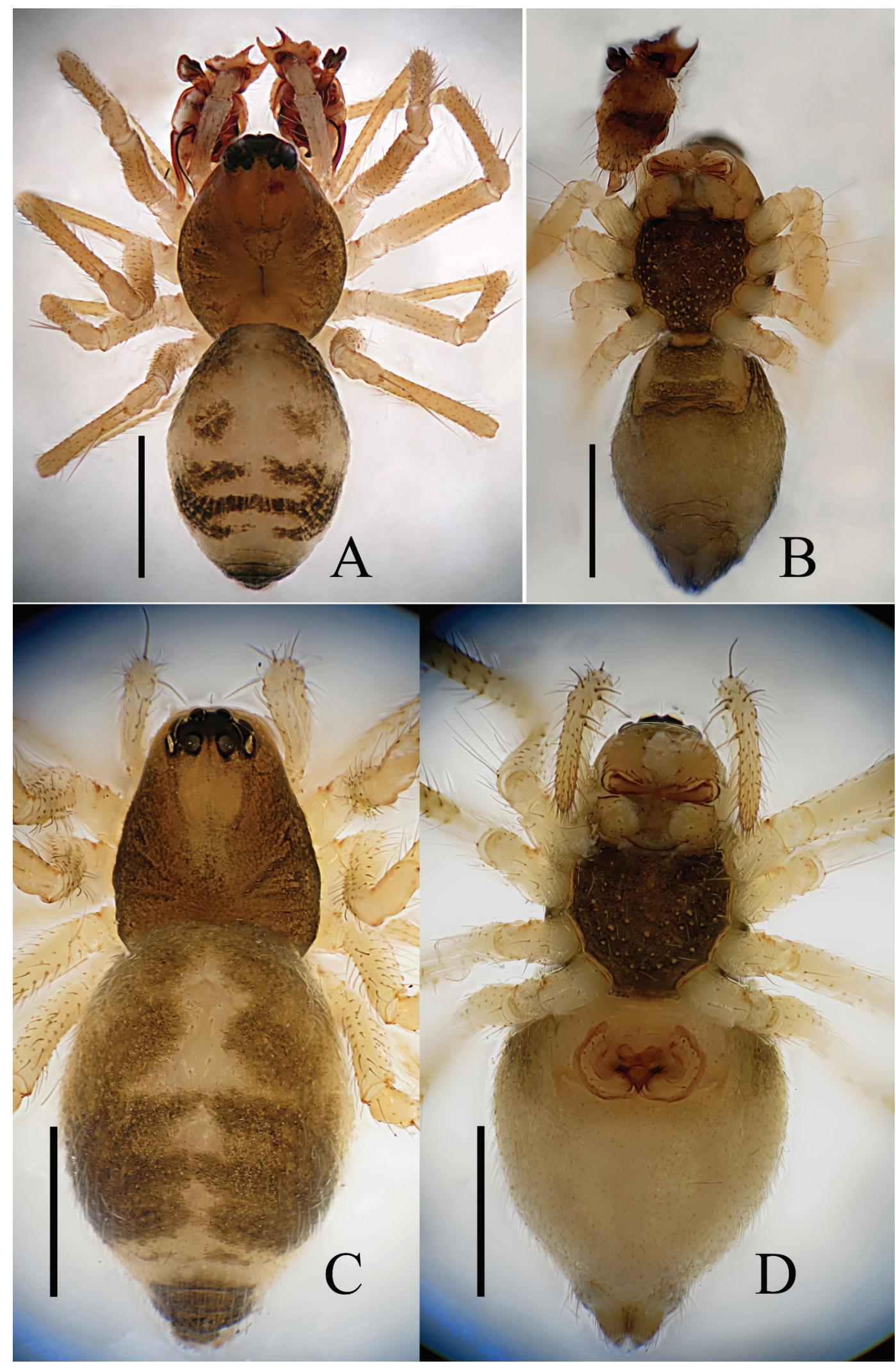

Fig. 1. Parbatthorax proiectus sp. nov., $O^{1}$, holotype (CGY107) (A-B) and $q$, one of the paratypes collected with the holotype (CGY107) (C-D). A, C. Habitus, dorsal view. B, D. Habitus, ventral view. Scale bars: $0.5 \mathrm{~mm}$. 


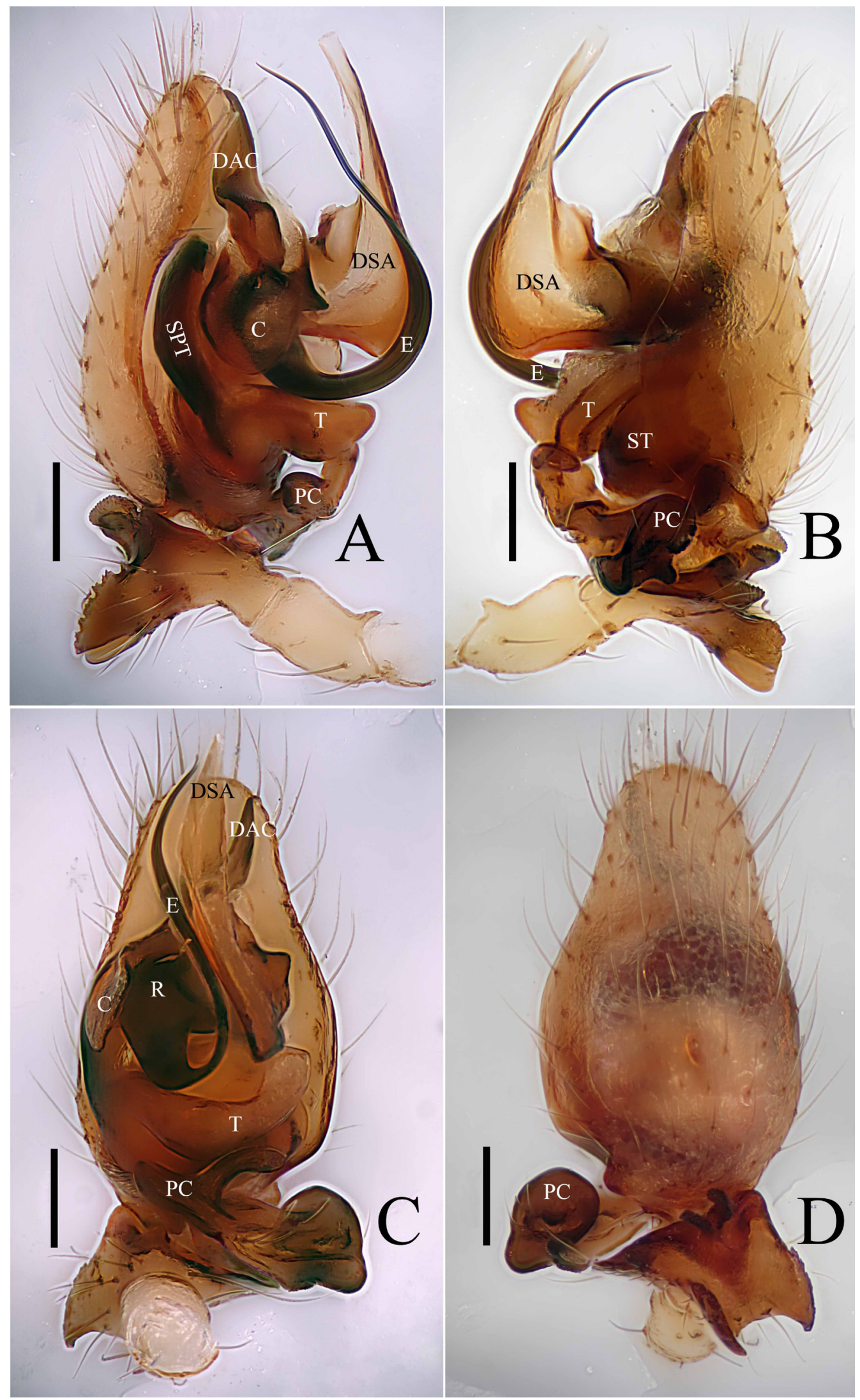

Fig. 2. Parbatthorax proiectus sp. nov., holotype, male palp (CGY107). A. Prolateral view. B. Retrolateral view. C. Ventral view. D. Dorsal view. Scale bars: $0.1 \mathrm{~mm}$. 

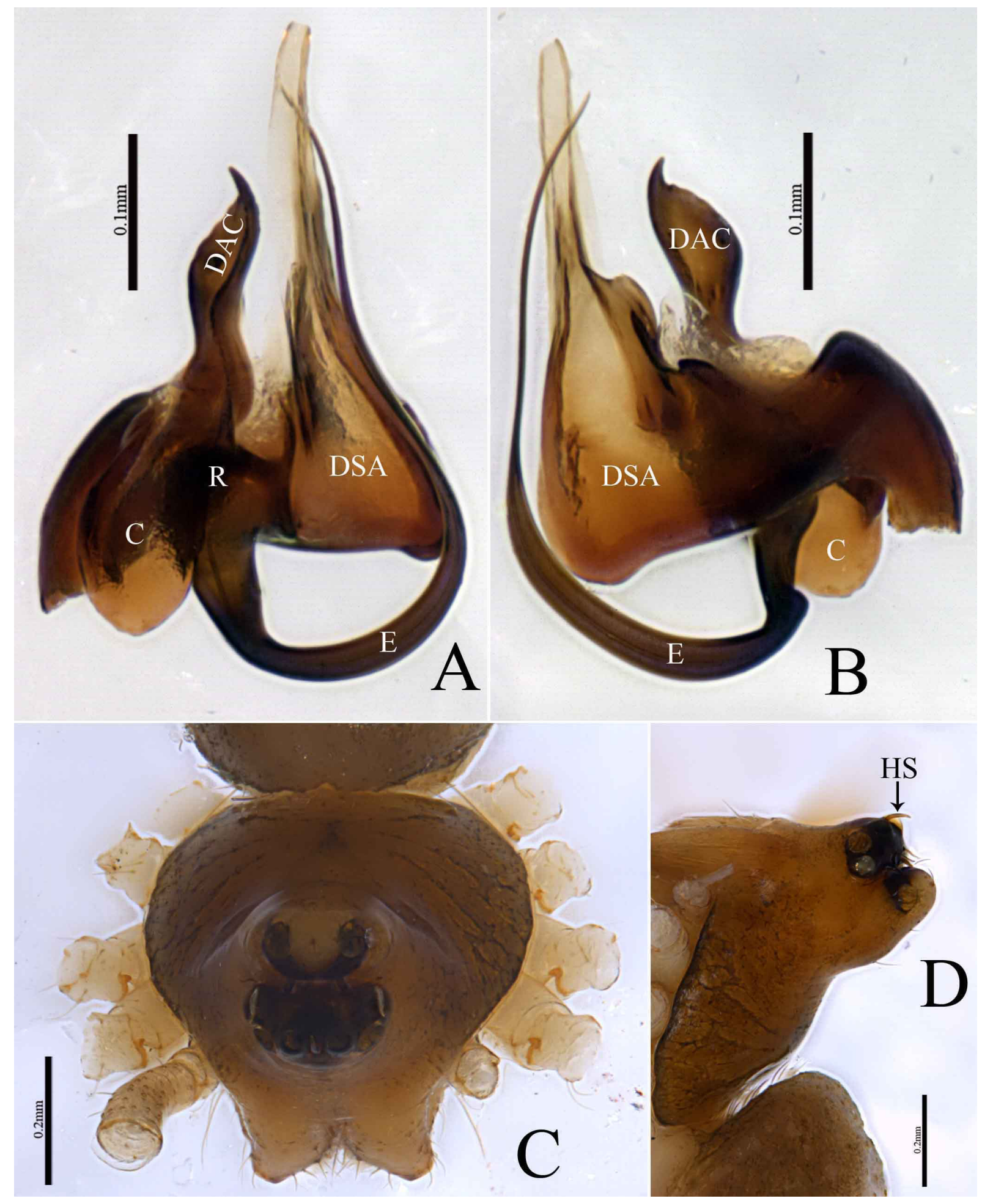

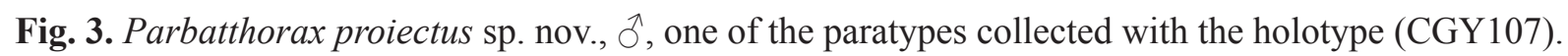
A. Embolic division, ventral view. B. Embolic division, retrolateral view. C. Cephalothorax, anterodorsal view. D. Prosoma, lateral view. Scale bars: A-B $=0.1 \mathrm{~mm} ; \mathrm{C}-\mathrm{D}=0.2 \mathrm{~mm}$. 
АвDомEN. 1.00 long, 0.68 wide, oval, grey, middorsally with broad light patch followed by three chevrons extending towards base of spinnerets, ventral side grey.

PaLp (Figs 2A-D, 3A-B, 4A-B). Patella as long as tibia; tibia short, distal part with four apophyses with teeth, looking like a flower in ventral view; paracymbium sclerotized, proximal part simple; distal arm highly modified, with a hook-shaped process. Tegulum excavated ventrally. Distal suprategular apophysis robust basally and narrowing gradually towards tip. Embolic division: convector round, with distal apophysis protruding upward; median membrane reduced; radix covered by convector in retrolateral view; embolus sclerotized, long, slightly curved and directed forward.

\section{Female}

Body AND HEAD. Total length 1.69-1.98. One of the paratypes (CGY107, Fig. 1C-D): total length 1.95. Carapace brown, 0.74 long, 0.61 wide, middorsally slightly elevated; fovea, cervical and radial grooves distinct. Clypeus 0.19 high. Sternum brown, wider than long, with spine-like hairs. Labium wider than long; maxillae long, distal end broad, with scopulae. Chelicerae with 4 promarginal and 5 retromarginal teeth. Eye region narrow, AER straight, PER procurved, slightly wider than AER. Eye sizes and interdistances: AME 0.05, ALE 0.05, PME 0.06, PLE 0.05, AME-AME 0.02, PME-PME 0.03, AMEALE, 0.01, PME-PLE 0.03, AME-PME 0.02, ALE-ALE 0.22, PLE-PLE 0.25, ALE-PLE contiguous.

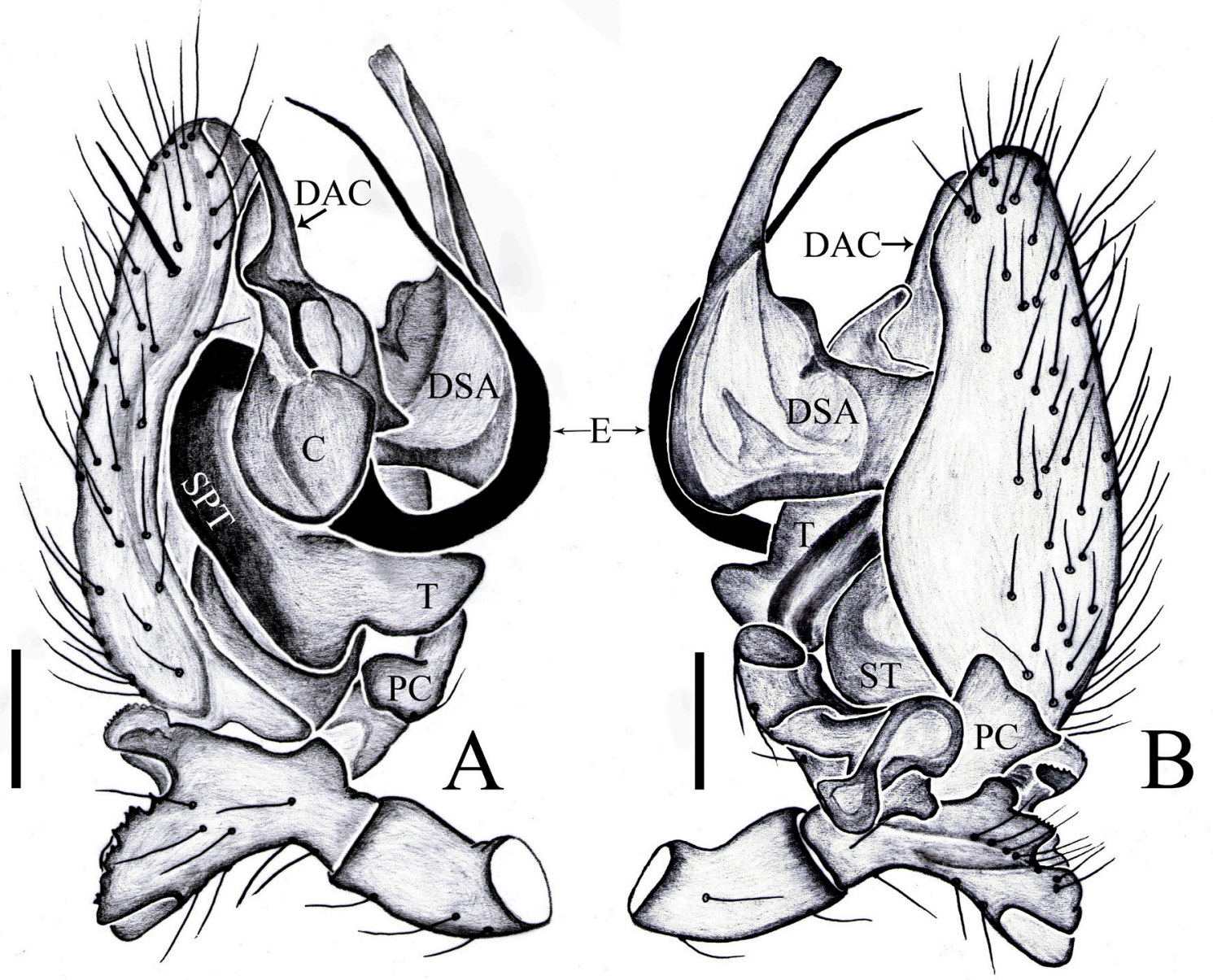

Fig. 4. Parbatthorax proiectus sp. nov., holotype, male palp (CGY 107). A. Prolateral view. B. Retrolateral view. Scale bars: $0.1 \mathrm{~mm}$. 
Leg MEASUREMENTS. I $2.66(0.79,0.82,0.68,0.37)$, II $2.65(0.76,0.85,0.66,0.38)$, III $2.11(0.65,0.63$, $0.51,0.32)$, IV $2.59(0.74,0.84,0.64,0.37)$.

Leg Formula. I-II-IV-III. TmI 0.29 and TmIV 0.21.

TiBIAL SPINE FORMULA. $2-2-1-1$.

Abdomen. Pale, 1.34 long, 1 wide, oval, all other morphological characters as in male.

Epigyne (Figs 5A-B, 6A-C). Wider than long, sclerotized; ventral plate wider than long, narrow posteriorly; copulatory opening located at posterior end between dorsal and ventral plates; dorsal plate sclerotized, wider than long.

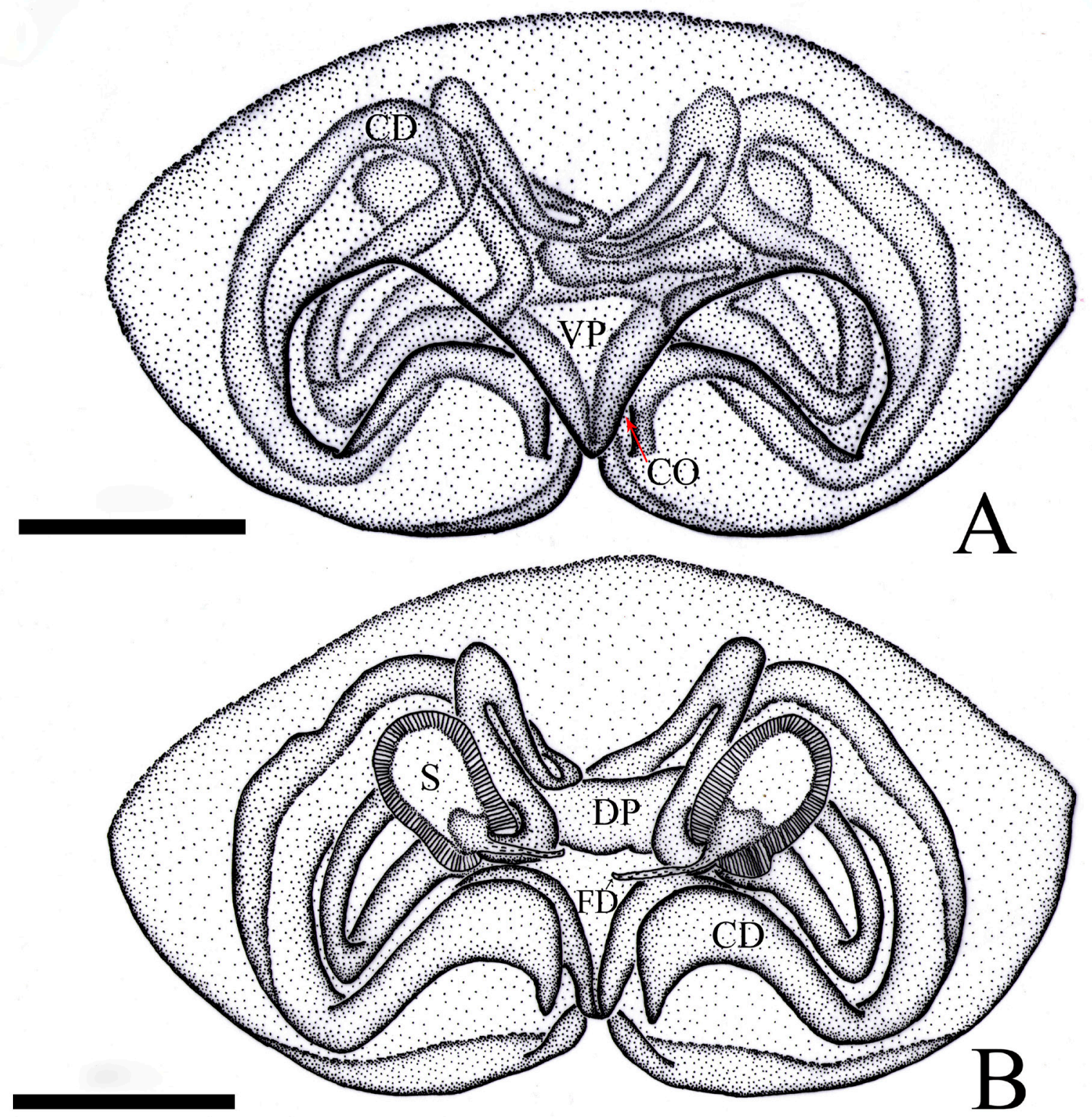

Fig. 5. Parbatthorax proiectus sp. nov., one of the paratypes collected with the holotype (CGY107). A. Epigyne, ventral view. B. Internal genitalia, dorsal view. Scale bars: $0.1 \mathrm{~mm}$. 


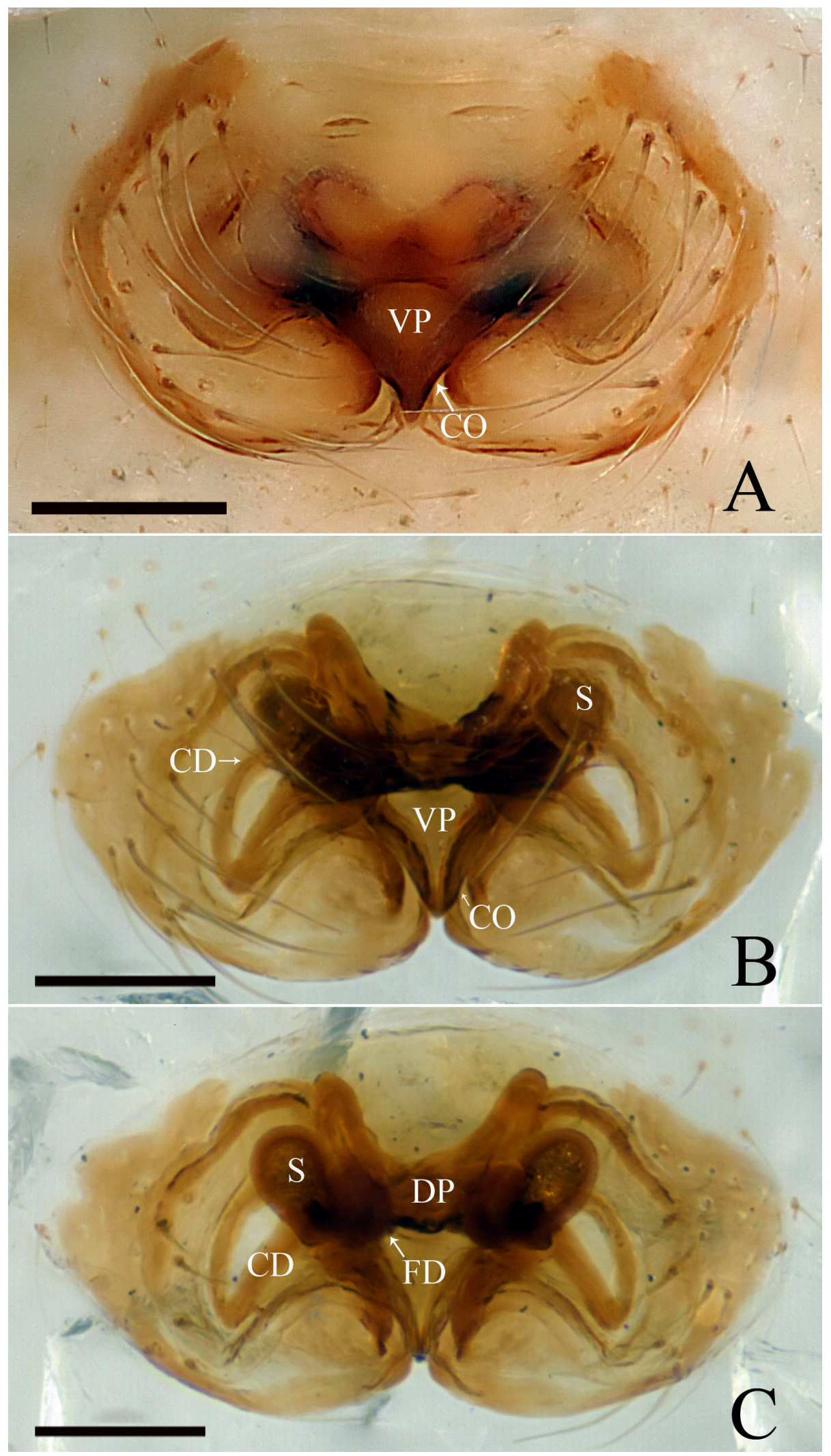

Fig. 6. Parbatthorax proiectus sp. nov., one of the paratypes collected with the holotype (CGY107). A. Epigyne, ventral view. B. Epigyne cleared, ventral view. C. Internal genitalia, dorsal view. Scale bars: $0.1 \mathrm{~mm}$. 
INTERNAL GENITALIA. Copulatory ducts sinuous, longitudinally folded laterally; spermathecae oval, present mesally, separated by a distance of two times of their width; fertilization ducts short, extending mesally.

\section{Distribution}

China (Yunnan, Fig. 7).

\section{Discussion}

The morphological characters of Parbatthorax proiectus sp. nov. are: male carapace modified with thick, horn-shaped spines; palpal tibia and paracymbium distinctively modified, with several projections; distal suprategular apophysis robust basally and narrowing gradually towards the tip; embolic division with distinct convector with distal apophysis; embolus sclerotized, curved, protruding upward. All the aforementioned characters characterize the new species as a member of the genus Parbatthorax Tanasevitch, 2019 (Figs 1-6; Tanasevitch 2019: figs 1-8).

\section{Acknowledgments}

We are grateful to Charles Griswold, Ming-wei Yang, Xin-ping Wang, Peng Hu and D.H. Kavanaugh for collecting the specimens. This research was sponsored by the National Science Foundation of the USA through the 'Joint Sino-American Biodiversity Survey, California Academy of Sciences (CAS)' with the grant "Biotic Survey of the Gaoligong Shan, a Biodiversity Hotspot in Western Yunnan, China" (No. DEB-0103795). It was also partly supported by the National Special Fund on Basic Research of Science and Technology of China (No. 2014FY110100), the Hunan Provincial Program for Development of Key Disciplines in Ecology (grant number No. 0713), the National Natural Sciences Foundation of China

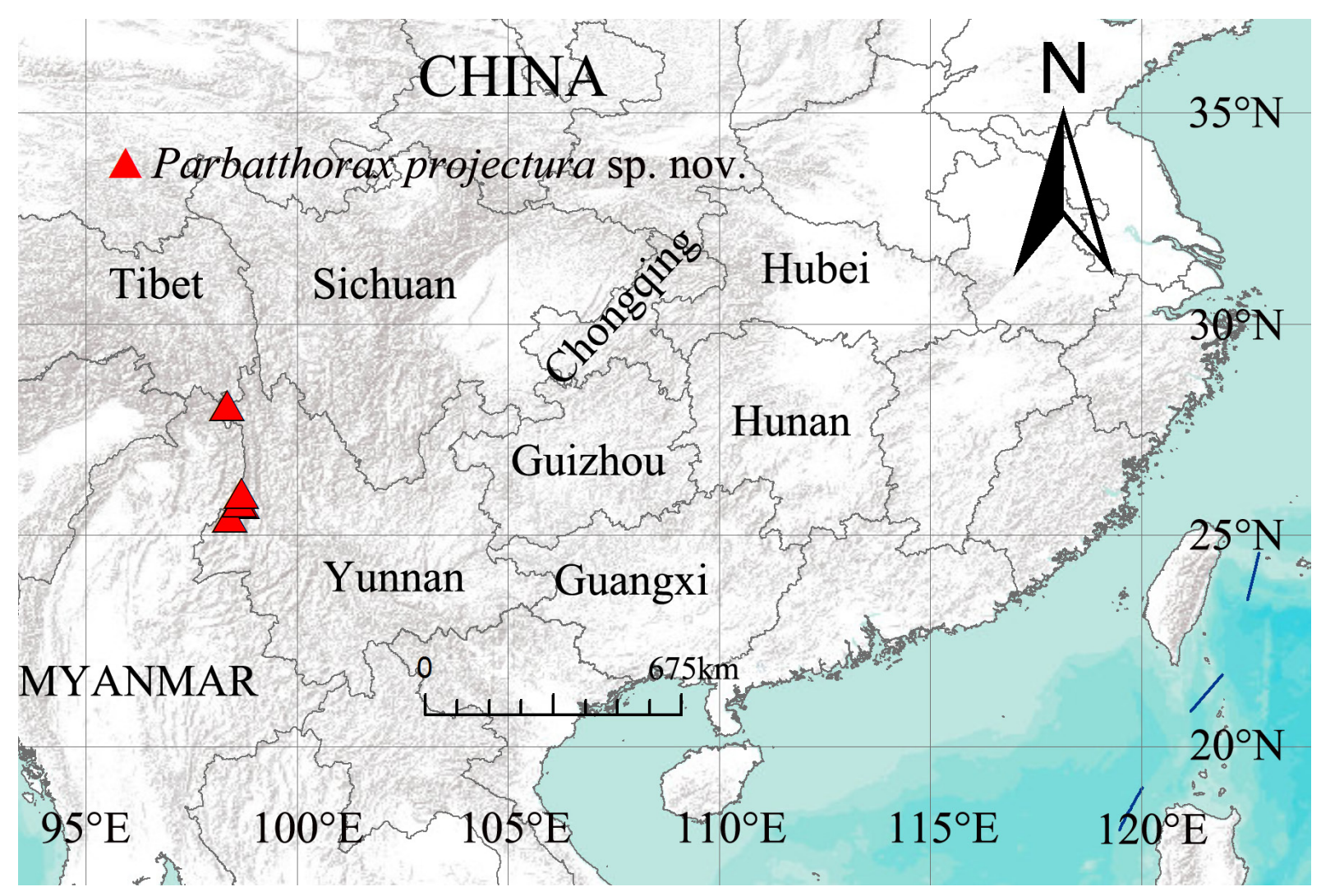

Fig. 7. Distribution of Parbattorax proiectus sp. nov. 
(NSFC-30970327, 31272271, 31272272, 31301861), the Hunan Provincial Natural Science Foundation of China (No.11JJ1004/12JJ3028), the Program for New Century Excellent Talents in University (NCET-12-0717), the China Postdoctoral Science Foundation (No. 20100471221/201104506), the program of the Hunan Provincial Science and Technology Plans (No. 2010RS4006) and the Hunan Provincial Innovation Foundation for Postgraduates (No. CX2017B182).

\section{References}

Irfan M. \& Peng X.J. 2018. Three new species of Linyphiidae (Arachnida: Araneae) from Yunnan, China. Oriental Insects 52 (3): 229-244. https://doi.org/10.1080/00305316.2017.1398115

Liu J. \& Chen J. 2010. A new species of the spider genus Neriene from Southwestern China (Araneae: Linyphiidae). Zootaxa 2483: 65-68.

Tanasevitch A.V. 2019. A new erigonine genus from the Nepal Himalayas (Araneae, Linyphiidae). Turkish Journal of Zoology 43 (2): 229-232.

Wunderlich J. \& Song D.X. 1994. Four new spider species of the families Anapidae, Linyphiidae, and Nesticidae from a tropical rain forest area of SW-China (Arachnida: Araneae). Beitrage zur Araneologie 4: 447-470.

Xia Q., Zhang G.R., Gao J.C., Fei R. \& Joo P.K. 2001. Three new species of spiders of Erigoninae (Araneae: Linyphiidae) from China. Korean Arachnology 17 (2): 161-168.

Zhao Q.Y. \& Li S.Q. 2014. A survey of linyphiid spiders from Xishuangbanna, Yunnan Province, China (Araneae, Linyphiidae). ZooKeys 460: 1-181. https://doi.org/10.3897/zookeys.460.7799

Manuscript received: 18 April 2019

Manuscript accepted: 28 June 2019

Published on: 20 September 2019

Topic editor: Rudy Jocqué

Desk editor: Kristiaan Hoedemakers

Printed versions of all papers are also deposited in the libraries of the institutes that are members of the EJT consortium: Muséum national d'Histoire naturelle, Paris, France; Meise Botanic Garden, Belgium; Royal Museum for Central Africa, Tervuren, Belgium; Royal Belgian Institute of Natural Sciences, Brussels, Belgium; Natural History Museum of Denmark, Copenhagen, Denmark; Naturalis Biodiversity Center, Leiden, the Netherlands; Museo Nacional de Ciencias Naturales-CSIC, Madrid, Spain; Real Jardín Botánico de Madrid CSIC, Spain; Zoological Research Museum Alexander Koenig, Bonn, Germany; National Museum, Prague, Czech Republic. 